\title{
THE SPLENDOUR OF THE MIDDLE JOMON CULTURE: CERAMICS FROM THE CENTRAL JAPANESE HIGHLANDS
}

The Japanese Jomon period, characterised by a prehistoric huntergatherer society with a vigorous material culture, is particularly noted for its long-lasting ceramic traditions. Currently enjoying great popularity in Japan, the Jomon culture remains largely unknown in Europe. This is due to its absence from most Japanese collections outside Japan - despite the efforts of several European museums in the 20oos to invite temporary exhibitions with representative Jomon 'national treasures' loaned from various Japanese museums. ${ }^{I}$ As it is impossible to do full justice to the regional and temporal diversity within the Jomon culture, this essay will introduce the most salient general aspects before focusing on the the Highlands in Central Honshu, an area that produced distinctive ceramics with evocative designs during the Middle Jomon phase (circa $3520-2470 \mathrm{BC}$ ) - to provide a glimpse into the variety of Jomon forms and iconography.

\section{A general background to the Jomon period (13,350-400 BC)}

The first inhabitants of Japan, and probable ancestors of the Jomon, were modern humans who arrived in the archipelago during the Late Pleistocene Ice Ages, about 40,00o to 35,00o years ago, via Okinawa and Hokkaido. They discovered local stone sources for manufacturing hunting tools, including obsidian (a volcanic glass highly suitable for sharp-edged tools such as spear points), and traded them over long distances. Around I6,500 years ago, nomadic hunters in Japan first started making pottery. This is one of the world's oldest ceramic traditions, roughly contemporaneous to, but probably independent from similar developments in China and Siberia. ${ }^{2}$ The added possibilities for cooking and storage proved to be a great boon, and pottery vessels soon became a permanent feature, making up a large proportion of finds at any Jomon excavation. Their location in the stratigraphy, combined with temporal typological changes, allows for extensive classification and chronology. Based on such finely-analyzed pottery typologies, the remarkably enduring Jomon period has been divided into six main phases: the Incipient, Initial, Early, Middle, Late and Final Jomon stages. ${ }^{3}$

As the climate gradually grew warmer, reaching a peak around $4000 \mathrm{BC}$, sea levels rose and deciduous tree types (including nut-bearing trees like U. hazelnuts, acorns and chestnuts) gradually spread across the archipelago. The result was an enormous expansion of dietary choices, both marine and forest-based, and Jomon populations throughout the archipelago started increasing; communities were able to settle in permanent villages and devote more time to craftsmanship and ceremony. The dominant subsistence mode based on fishing, hunting and gathering food plants $_{023}$ 03:29:31 Am 

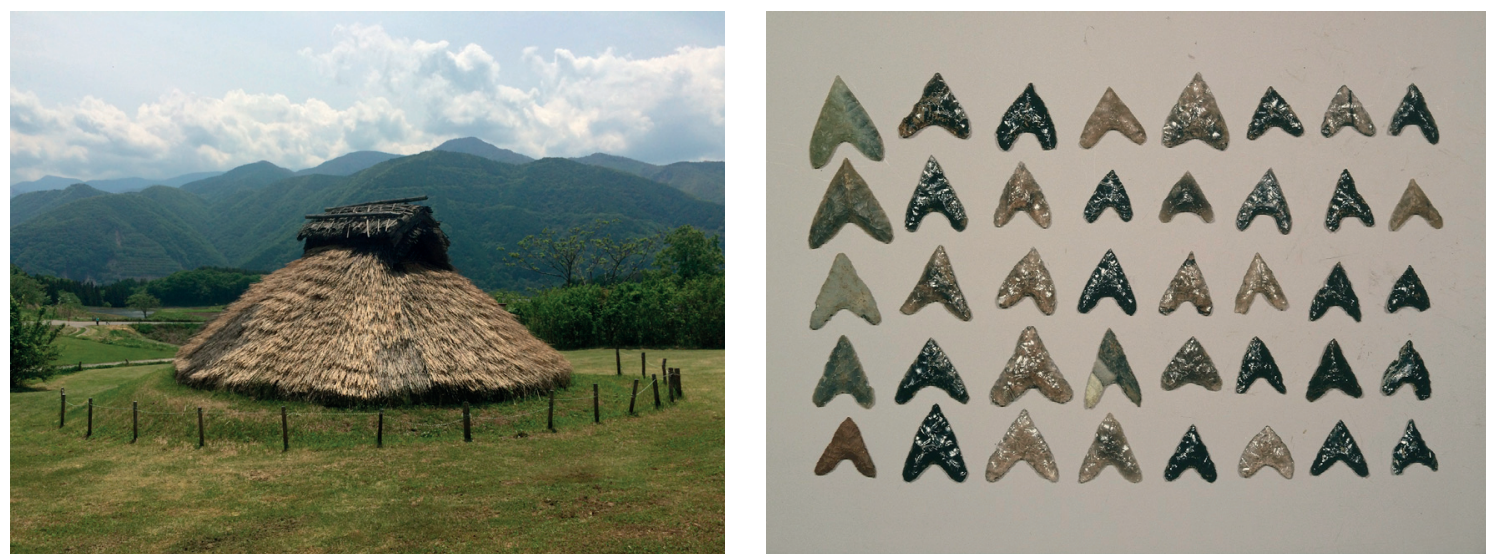

Fig. 1 (left)

Reconstruction of a Jomon 'pit-dwelling' house in Fujimi, near the Idojiri Archaeological Museum. Excavations of long-term settlements can yield hundreds of such house pits, with ten or more used contemporaneously during population booms

Fig. 2 (right) Arrowheads, mostly made of obsidian from the local source in the Yatsugadake mountain range; height of arrowhead in upper left corner: $3.1 \mathrm{~cm}$, Tsukuehara site, Idojiri Archaeological Museum. The obsidian from this source is translucent and varies in colour from very light to a dark, smoky grey. The five items on the far left are made of other materials, such as chert (depending on the local environment and available resources) would continue throughout the period - sometimes supplemented with minor horticultural activities. ${ }^{4}$ In the Central Highland, these conditions led to the apogee of the local Jomon culture during the subsequent Middle Jomon phase.

The Jomon people inhabited the full spectrum of Japanese landscapes; in the mountains, by lakes and rivers, at the coast, and at the junctions of lagoons and forests. While all Jomon sites feature large quantities and varieties of ceramic and stone objects, the coastal kaizuka shell middens (mounds several metres deep, consisting of thick layers of discarded shells mixed with organic materials, bones and occasional artefacts) and lowland waterlogged sites with well-preserved organic materials, are other treasure troves of knowledge for archaeologists. These include food waste; tools and ornaments made of animal bone, antler, shell and wood; textiles and baskets woven from tree bark and flax; and even ceramics and ornaments decorated with beautiful red and black lacquer. ${ }^{5}$ Well-preserved human bones have shed light on health, diet, mobility and human burial practices.

Jomon people were relatively robustly built and short in stature (on average I.57 metres tall for men; under I.50 metres for women) and had double-lidded eyes. They often wore jewellery (pendants, ear and hair ornaments, bracelets) made of stone, animal teeth, bone, antler, shell, wood or clay. Preserved skulls show that some groups practiced dental modification, extracting certain teeth, possibly during rites of passage. Clay figurines suggest a range of hairstyles, and possibly even tattooing. Rare pendants made of jadeite and amber from the Japan Sea and Pacific Coasts, respectively, were imported over long distances; these were valued very highly and probably represented aspects of identity and well-being to some communities, families or occupational groups. ${ }^{6}$ In addition to abundant bodily and ceramic ornamentation, several artefact types reflect the Jomon worldview and spirituality especially from the tho $_{023}$ 03:29:31AM 

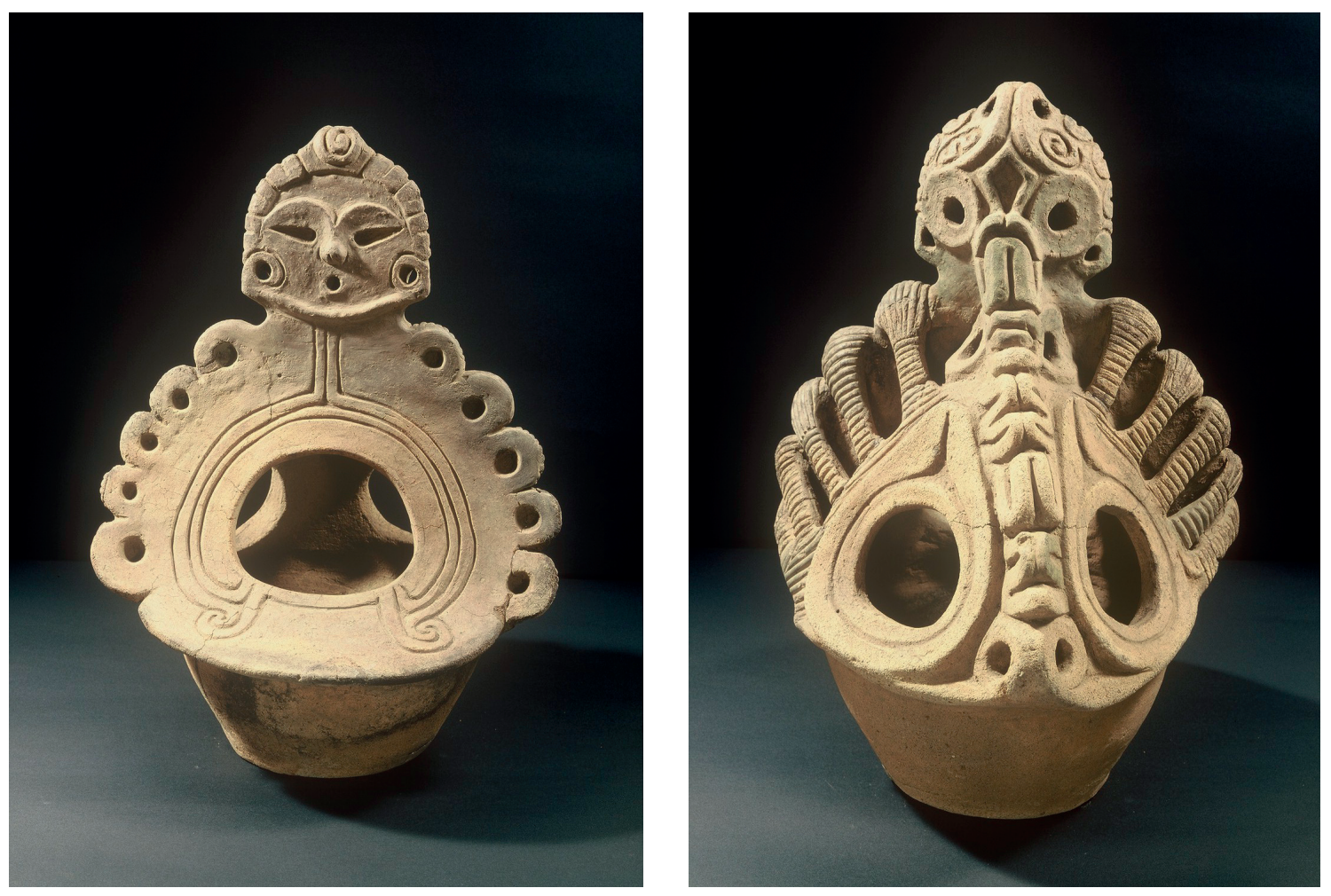

Fig. 3 a and b Katsusaka-style ceremonial lamp, decorated with human face, back and front view, $h$. $47.7 \mathrm{~cm}$, Sori site, Idojiri Archaeological Museum. When seen from the back the hairstyle or headdress of the human head is said to form another, abstract 'monster face'
Middle Jomon onwards; such as large phallic ceremonial stone objects and particularly iconic clay figurines.

Due to their skill in adapting to diverse landscapes, the fact that they lived in permanent villages, and their craftsmanship in ceramics, stone and lacquer-work, the Jomon are often referred to as 'complex huntergatherers'. Interestingly, there is little or no evidence of (pronounced) social differentiation; the Jomon communities were more or less egalitarian, with no indication (so far!) of sustained inter-communal conflict. ${ }^{7}$ However, it should be emphasised that there was tremendous temporal and spatial diversity during the Jomon period, not only in terms of lifestyle adaptations to different environments, but also ceramic styles that reflected local customs and beliefs. ${ }^{8}$

\section{Artefacts from the Middle Jomon culture in the Central Japanese Highlands}

The Central Highlands in present-day Nagano and Yamanashi flourished during the 4th-3rd millennium $\mathrm{BC}$, when a rapidly expanding population accumulated in sizeable villages and produced large quantities of distinctive ceramics. ${ }^{9}$ This essay introduces some representative examples from the Idojiri Archaeological Museum in Fujimi, Nagano prefecture, excavated from surrounding Jomon villages in the mountains above Lake Suwa. These villages enjoy a spectacular landscape that, weather permitting, even includes a distant view of Mount Fuji, which is still regarded as Japan's most sacred mountain. One of the greatestasssets _of $03: 29: 31 \mathrm{Am}$ 
this region was high-quality obsidian, which circulated widely through Japan, either as a raw material or as finished, locally produced arrowheads (fig. 2). The mountain communities maintained cordial contacts with those in distant areas - notably the Japan Sea Coast and Tokyo Bay area, as is testified by the presence of 'imports' such as ceramics and relatively large quantities of jade and amber pendants. Nevertheless, this area is most famous for its ceramics: a great diversity in pottery vessels and clay figurines, whose iconography suggests an elaborate cosmology.

Fig. 4 (below left) Early Sori-style vessel with geometric designs and asymmetric, prominent spiralling rim protrusions, h. $43 \mathrm{~cm}$, Sori site, Idojiri Archaeological Museum

Fig. 5 (below right) Late Middle Jomon vessel with wide rim and geometric pattern, h. $75 \mathrm{~cm}$,

Todonomiya site, Idojiri Archaeological Museum
As with all Jomon pottery, the vessels were built up from clay coils, with textures and applications added later. The potter's wheel was unknown, as was the ceramic kiln. Finished pots were dried, then fired in the open at temperatures as low as $500-600^{\circ}$ Celsius. Middle Jomon pots tend to be rather thick-walled, especially when compared to the thinner and harder Final Jomon pottery. Pottery from the earlier half of the Middle Jomon, collectively known as 'Katsusaka style' is very distinctive from the later 'Sori style', both in terms of form and decorative patterns.

Asymmetrical designs are representative of many Middle Jomon vessels. The iconography from the early half of the Middle Jomon is exuberant, including geometric motifs; appliqués of zoomorphic motifs such as snakes, frogs, and abstracted amphibian figures; as well as a variety of anthropomorphic motifs. Some objects have appliqués of dynamic, abstract 'dancing' humanoid forms decorating the body, or threefingered figures straddling the pot. Although wide-rimmed, deep cooking vessels are most widespread, other forms are present as well, such as
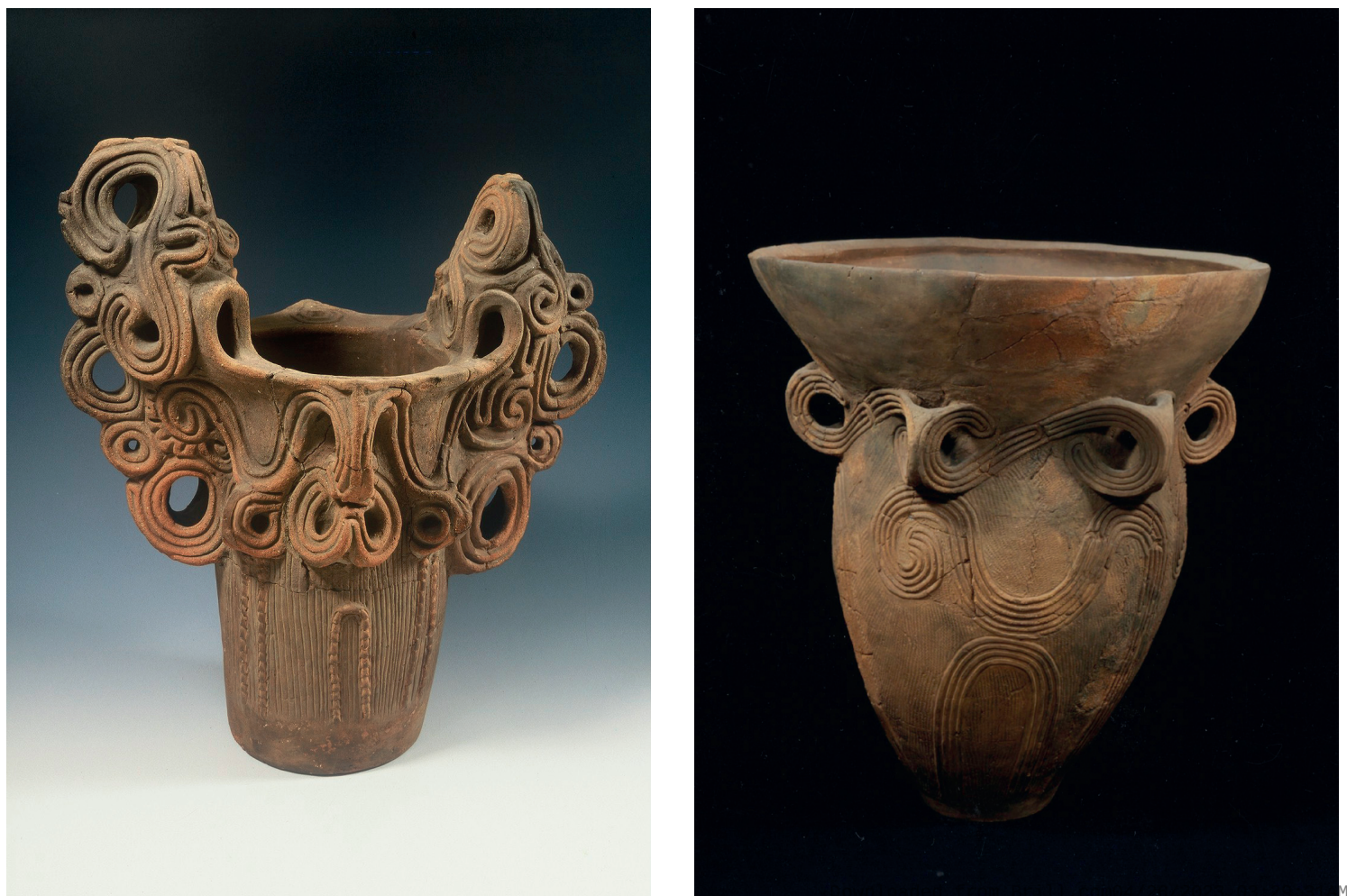


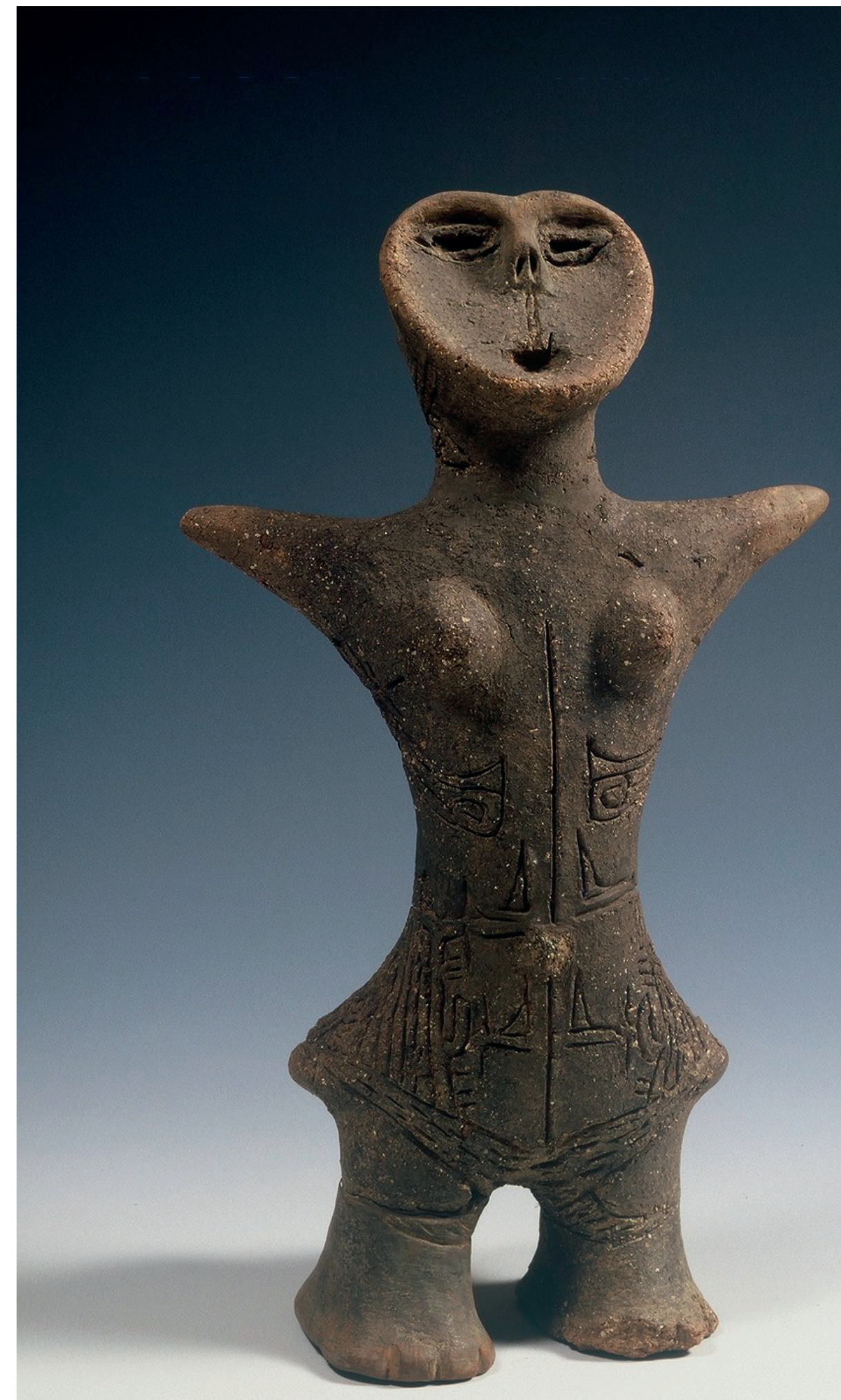


Fig. 6 (left)

Sori-style clay figurine, h. $23 \mathrm{~cm}$, Sakaue site, Idojiri Archaeological Museum, Important Cultural Property. Extremely rare complete figurine, found in a special 'figurine burial' context. Its style is distinct from the earlier Katsusaka style ceremonial lamps. ${ }^{10}$ Examples topped with an anthropomorphic head are extremely rare (fig. 3). Another representative type is the wide jar with a flanged and pierced rim, suggesting its mouth was covered by animal skin. Most interpretations propose its function either as a 'drum' or as a 'fermentation vessel for producing alcohol'.

The later Middle Jomon 'Sori style' ceramics discarded the anthropomorphic and zoomorphic elements, displaying abstract, geometric designs instead (fig. 4) - sometimes still featuring extravagant, undulating or spiralling rim projections (fig. 5). During the Middle Jomon period, the people of the Central Highlands vigorously practiced ceremonies featuring clay figurines. In $99 \%$ of cases, these ceremonies involved their deliberate fragmentation, with parts being scattered around the settlement or even shared with other settlements. In extremely rare cases, a complete figurine is discovered, always in an exceptional context; such as the unique Sori figurine that was buried in the village centre, probably as the community's guardian deity (fig. 6). While there are many different types, most figurines exhibit some feminine characteristics, sometimes showing various stages of pregnancy. ${ }^{\mathrm{II}}$

\section{Conclusion}

What does it all mean? Most regard the iconography as representing deities and legends associated with local identities. While archaeologists hesitate to further 'decipher' prehistoric symbols without factual context, folklorists are happy to take on this task. Drawing comparisons with Middle Eastern iconography and later Japanese mythology, Nelly Naumann has proposed that the assorted Katsusaka pottery design elements (crescents, moon-faced rim-heads, three-fingered figures, frogs and snakes, together with the broken figurines) represented a lunar cult concerned with concepts of life, death, and rebirth - also involving water and the fertility cycles of women and the natural world. ${ }^{12}$ Folklorist Atsuhiko Yoshida has linked the presence of the anthropomorphic vessel decorations and broken figurines to the mythical motif of a sacrificed fertility goddess whose severed body parts turned into abundant crops for the benefit of humanity. A similar goddess is mentioned in Japan's earliest historical anthology, the Kojiki, and is also found as a more universal Pacific mythical component: the sacrificial goddess Hainuwele.

As for the clay-figurine rituals, interpretations are legion. In addition to the 'mother goddess' and universal 'fertility, rejuvenation and cycles of nature' hypotheses, the 'vicarious substitute' (involving healing rites by which injuries or illnesses are transferred to the figurines) is also popular.13 An association with 'crops' is a widely held interpretation in this mountain region, due to a long-standing theory that the local Central Highlands Jomon culture practiced some form of cultivation to sustain its large population. While the presence of enormous quantities of hoe-like stone tools at sites in this area supports this theory, no conclusive evidence of cereal cultivation has so far been detected, although tubers such as yams remain a possibility. ${ }^{14}$ 
Local pride in this Jomon culture is evident at the nearby Shinano-Sakai train station, which features a small display of regionally crafted replicas of the most iconic ceramics at the Idojiri Archaeological Museum.

However, this is by no means the only well-loved Jomon culture in Japan. Other examples of contemporaneous Middle Jomon cultures are the iconic 'Flame-rimmed pottery' group from Niigata's 'Snow Country', and the northeastern Jomon culture surrounding Aomori's Sannai-Maruyama site (Japan's most famous Jomon settlement).

Universally viewed as a peaceful culture living in harmony with nature, the creative spirit of the Jomon has captured the hearts and imagination of present-day Japanese.

- Ilona Bausch specialises in East Asian and Japanese archaeology, with a focus on the Jomon culture. After studying at Kokugakuin University in Tokyo and Durham University (Ph.D.), she lectured part-time at Leiden University. In 2014 (until 20I7) she became Project Associate Professor at the Department of Cultural Resource Studies at Tokyo University. Other research interests include the history of Japanese collections in Europe, and the popular representation of Japanese archaeology within contemporary society.

\section{LITERAT URE}

Gina Barnes, Archaeology of East Asia: The Rise of Civilization in China, Korea and Japan, Oxbow Books, Oxford, 2015.

Ilona Bausch, "The Materiality and Social Value of Amber Objects During the Middle Jomon in Japan', Analecta Praehistorica Leidensia 43/44 (2012), pp. 22I234.

Ilona Bausch, 'Jade Landscapes: Changing Social Values of Jade in Jomon Japan', in: Neomap Project (ed.), Studies of Landscape History on East Asian Inland Seas, Research Institute for Humanity and Nature, Kyoto, 20Ioa, pp. 57-68.

Ilona Bausch, 'Fragmentation Practices in Central Japan: Middle Jomon Clay Figurines at Shakado', in: Dragoş Gheorghiu and Ann Cyphers (eds.), Zoomorphic Miniature Figures in Eurasia, Africa and Meso-America: Morphology, Materiality, Technology, Function and Context, Archaeopress, Oxford, 20Iob, pp. 99-II2.

Junko Habu, Ancient Jomon of Japan, Cambridge University Press, Cambridge, 2004.

Keiji Imamura, Prehistoric Japan: New Perspectives on Insular East Asia, UCL Press, London, 1996.

Simon Kaner (ed.), The Power of Dogu: Ceramic Figurines from Ancient Japan, British Museum, London, 2009.

Tatsuo Kobayashi, Jomon Reflections: Forager Life and Culture in the Prehistoric Japanese Archipelago, Oxbow Books, Oxford, 2004.

Nelly Naumann, Japanese Prehistory: The Material and Spiritual Culture of the Jōmon Period, Harrassowitz Verlag, Wiesbaden, 2000.

Richard Pearson, 'Debating Jomon Social Complexity', Asian Perspectives 46 (2007), pp. 36I-388.

Mariko Yamagata, "The Shakado Figurines and Middle Jomon Ritual in the Kofu Basin', Journal of Religious Studies 19/2 (1992), pp. I29-I38.

Alfried Wieczorek and Werner Steinhaus (eds.), Zeit der Morgenröte: Japans Archäologie und Geschichte bis zu den ersten Kaisern (2 volumes), ReissEngelhorn Museen, Mannheim 2004. 
* Photographs: Fig. I bij Ilona Bausch. Fig. 2 by Idojiri Archaeological Museum. Figs. 3-7 by Mikihiro Taeda (courtesy of the Idojiri Archaeological Museum, Fujimi, Nagano Prefecture).

I Temporary exhibitions in Europe at this time included the Power of Dogu: Ceramic Figures from Ancient Japan exhibition in the British Museum (Kaner 2009, focusing on Jomon ceramics, rituals and iconography), and the comprehensive Zeit der Morgenröte on Japanese archaeology in Berlin (Wieczorek and Steinhaus 2004). The British Museum permanently exhibits a small selection of Jomon ceramics and artefacts in its Japan Gallery. In the Netherlands, only the Siebold Museum in Leiden currently displays Jomon objects: a small number of stone tools that were brought to the Netherlands in the I83os as part of Philip Franz von Siebold's collection.

2 Habu 2004: 26-42. The oldest Jomon ceramics discovered so far were found in the southwestern and northeastern peripheries of Japan.

3 Barnes provides the most recent chronology, combining the pottery-based typology with calibrated radiocarbon dates:

Incipient (13,350-10,550 BC)

Initial (IO,550-5050 BC)

Early $(5500-3520 \mathrm{BC})$

Middle (3520-2470 BC)

Late (2470-I250 BC)

Final Jomon (1250-970 BC for Southwest Japan; 1250-400 BC for Northeast Japan)

- until large-scale migrations via the Korean Peninsula introduced rice-paddy agricultural and sociopolitical systems, initiating the subsequent Yayoi period. See Barnes 2015: 23.

4 Barnes 20I5: III-II4. Known cultivation practices included the manipulation of nut-bearing trees. Domesticated plants such as beans, herbs, barnyard millet and gourds formed only a minor addition to the diet. Until the advent of continental rice-paddy cultivation, the Jomon never turned to full-scale farming.

5 Pearson 2007: 366-369. The oldest lacquerware dates to $7000 \mathrm{BC}$, indicating that it may have been an independent Jomon invention.

6 Bausch 2010a; 2012.

7 Habu 2004; Pearson 2007; Barnes 2015.

8 Kobayashi 2004: chapters 3-4. Kobayashi has extensively researched the regional and temporal variety of the Jomon pottery styles and designs, and mapped their distribution. Although Japanese archaeologists usually shy away from making assumptions about past ethnicities, he has proposed that spatially different ceramic style groups corresponded with the territories of distinct social groups with their own cultural identity, traditions, and probably dialects.

9 Imamura 1996: 93-96.

Io Kaner 2009: 137. One of these objects still contained its wick, shedding light on its function.

II Bausch 20Iob.

I2 Naumann 2000. Her work remains very influential among Japanese folklorists in this region.

I3 Yamagata 1992; Bausch 20Iob.

I4 Imamura 1996: I09; Takashi Komatsu, curator at the Idojiri Archaeological Museum and excavator of local Jomon sites (personal communication, I4 May 20I6). 